\title{
Trends and outcomes of women with synchronous endometrial and ovarian cancer
}

\author{
Koji Matsuo ${ }^{1,2}$, Hiroko Machida ${ }^{1}$, Erin A. Blake ${ }^{1}$, Laura L. Holman ${ }^{3}$, Bobbie J. Rimel ${ }^{4}$, \\ Lynda D. Roman ${ }^{1,2}$ and Jason D. Wright ${ }^{5}$ \\ ${ }^{1}$ Division of Gynecologic Oncology, Department of Obstetrics and Gynecology, University of Southern California, Los Angeles, \\ CA, USA \\ ${ }^{2}$ Norris Comprehensive Cancer Center, University of Southern California, Los Angeles, CA, USA \\ ${ }^{3}$ Division of Gynecologic Oncology, Department of Obstetrics and Gynecology, University of Oklahoma Health Sciences \\ Center, Oklahoma City, OK, USA \\ ${ }^{4}$ Division of Gynecologic Oncology, Cedars-Sinai Medical Center, Los Angeles, CA, USA \\ ${ }^{5}$ Division of Gynecologic Oncology, Department of Obstetrics and Gynecology, Columbia University College of Physicians and \\ Surgeons, New York, NY, USA \\ Correspondence to: Koji Matsuo, email: koji.matsuo@med.usc.edu \\ Keywords: endometrial cancer; ovarian cancer; trend; survival; synchronous \\ Received: December 21, $2017 \quad$ Accepted: May 16, $2018 \quad$ Published: June 19, 2018 \\ Copyright: Matsuo et al. This is an open-access article distributed under the terms of the Creative Commons Attribution License \\ 3.0 (CC BY 3.0), which permits unrestricted use, distribution, and reproduction in any medium, provided the original author and \\ source are credited.
}

\section{ABSTRACT}

This retrospective observational study examined trends, characteristics, and survival of women with synchronous endometrial and ovarian cancer (SEOC) in the Surveillance, Epidemiology, and End Results Program between 1973 and 2013. Among 235,454 women with primary endometrial cancer, synchronous ovarian cancer was seen in $4,082(1.7 \%)$ women with the proportion being decreased from $2.0 \%$ to $1.6 \%$ between 1983 and $2013(P=0.049)$; and the proportion of concurrent endometrioid tumors in the two cancer sites has increased from $24.2 \%$ to $49.9 \%$ among SEOC women $(P<0.001)$. When compared to endometrial cancer without synchronous ovarian cancer, endometrioid histology in the two cancer sites was associated with improved cause-specific survival while non-endometrioid histology in the ovarian cancer was associated with decreased cause-specific survival (adjusted$P<0.01)$. Among 110,063 women with primary epithelial ovarian cancer, synchronous endometrial cancer was seen in 3,940 (3.6\%) women with the proportion being increased from $2.2 \%$ to $4.4 \%$ between 1973 and $2013(P<0.001)$; and the proportion of concurrent endometrioid tumors in the two cancer sites had increased from $24.3 \%$ to $50.2 \%$ among SEOC women $(P<0.001)$. When compared to primary epithelial ovarian cancer without synchronous endometrial cancer, SEOC was associated with better cause-specific survival if ovarian cancer is endometrioid type or if endometrial cancer is endometrioid type (adjusted-P<0.001). Across the two cohorts, the proportion of SEOC reached to the peak in the late-40 years of age and then decreased significantly $(P<0.001)$. In conclusion, our study suggests that synchronous ovarian cancer has decreased among endometrial cancer whereas synchronous endometrial cancer has increased among epithelial ovarian cancer.

\section{INTRODUCTION}

Synchronous endometrial and ovarian cancer (SEOC) is defined as the simultaneous presence of these two cancers at the time of diagnosis as opposed to metachronous cancer where these two cancers are diagnosed at different chronologic time points. SEOC is not a rare clinical entity; it has been reported in $3-10 \%$ 
of ovarian cancers and $3-5 \%$ of endometrial cancers [14]. The substantial range of incidences for synchronous endometrial cancer in ovarian cancer may be due to the small sample sizes in the majority of prior analyses. In addition, population-based statistics are missing regarding the incidence of synchronous ovarian cancer in endometrial cancer.

The diagnosis of SEOC is generally made by histopathologic evaluation. The landmark criteria for the diagnosis of SEOC were established by Ulbright and Roth in 1985, and more solid criteria were endorsed by Scully et al in 1998 [5-7]. To date, the impact of these diagnostic criteria on the incidence trend of SEOC is not known. Historically, women with SEOC, specifically those who have concordant endometrioid tumors in the two cancer sites, have been thought to have a favorable prognosis [1, 7]. Because prior studies evaluating prognosis have lacked a control group of endometrial cancer without synchronous ovarian cancer, the histologic pattern-specific survival of women with synchronous tumors relative to those without synchronous tumors will be useful to understand the clinical characteristics of this disease entity.

In the past decades, the demographics of endometrial cancer and ovarian cancer have been changing in the United States. There has been a gradual increase in incidence of endometrial cancer most likely due to the significant increase in obesity $[8,9]$. Moreover, there is a steady decrease in incidence of ovarian cancer likely due to the introduction of oral contraceptive use and reduction in menopausal hormone therapy [10-12]. Given these recent changes in demographics, it is of interest to understand the time-trends of SEOC in the United States. The objective of the study was to examine populationbased trends, characteristics, and survival outcome of women with SEOC.

\section{PATIENTS AND METHODS}

\section{Data source and eligibility}

This retrospective study utilized the Surveillance, Epidemiology, and End Results (SEER) Program that is a population-based tumor registry in the United States [13]. This database was provided and has been maintained by the National Cancer Institute since 1973. The SEER database covers approximately $28 \%$ of the US population and is publicly available and de-identified. The data entry to this database is performed by staff personnel who are trained by the National Cancer Registrars Association with rigorous quality control [14]. The Institutional Review Board at the University of Southern California exempted this study. The STROBE guidelines were used to outline the performance of this observational study [15].

SEER*Stat 8.3.2 (IMS Inc., Calverton, MD, USA) was used to extract the SEER18 cases (1973-2013), generating the dataset from "Corpus Uteri / Uterus NOS" limited to malignancy and female sex. Primary endometrial cancer cases were eligible for the study, excluding sarcoma or metastatic tumors to the uterus from another origin. SEER*Stat 8.3.2 was also used to generate primary ovarian cancer cases for the same study period. Then, the ovarian cancer dataset was linked with the aforementioned endometrial cancer dataset. The same study identification numbers between the two datasets were considered secondary primary cancer in the same individual as described previously [16-18]. This methodological approach was based on the rationale that the SEER Program maintains the records per cancer type but not an individual basis.

The chronologic time sequence of the endometrial cancer diagnosis date and the ovarian cancer diagnosis date were then examined among the cases recorded in the two datasets. The cohort cancer was used as the index cancer whereas the non-cohort cancer represented the secondary primary cancer to determine this time interval for each cohort. Women in whom the time intervals between the two diagnoses were less than 4 months were considered synchronous ovarian cancer in the endometrial cancer cohort. The cutoff value of a 4-month time interval between the two cancer diagnoses is based on the rationale that endometrial cancer is commonly diagnosed via endometrial sampling prior to hysterectomy and ovarian cancer is generally diagnosed at the time of subsequent hysterectomy. Waiting time for hysterectomy-based surgery after endometrial biopsy in women with endometrial cancer commonly reflects time interval for patient referral to specialty and optimization of medical condition as women with endometrial cancer often possess multiple comorbidities. The vast majority of women with endometrial cancer undergo hysterectomy within 4 months of diagnosis [19-21].

A similar approach was performed to generate the epithelial ovarian cancer cohort, and the dataset was linked to the endometrial cancer dataset to identify the secondary primary cancer cases. The ovarian cancer cohort did not include non-epithelial histologies. We also used the 4-month cutoff to define the synchronous endometrial cancer cases in the epithelial ovarian cancer cohort to be consistent with the endometrial cancer cohort. Time interval analyses between the two cancer diagnoses among secondary primary cancer cases relative to an endometrial cancer diagnosis showed that nearly half $(54.5 \%)$ of secondary primary cancers were diagnosed at the same time and that the vast majority of cases $(86.2 \%)$ were diagnosed within 4 months (Supplementary Figure 1).

\section{Clinical information}

Among the eligible cases for analysis, patient demographics, tumor information, treatment patterns, and survival outcome were ascertained from the database. Patient demographics included age, year and month at diagnosis, ethnicity, marital status, and registration area. Tumor information included cancer stage, histologic 
subtype, tumor grade, and tumor size. Cause-specific survival (CSS), defined as the time interval between the date of cancer diagnosis and the date of death from the corresponding cancer, was examined for survival outcome. SEER Cause Specific Death Classification was utilized to determine CSS, and the code representing "death attributable to this cancer diagnosis" was used as a surrogate for CSS, and the code representing "death attributable causes other than this cancer diagnosis" was not used for CSS. Cause of death in this database is linked with the National Death Index and the state mortality records [22].

Recorded cancer stage was based on the American Joint Committee on Cancer 7th surgical-pathological staging classification schema [23]. The International Classification of Diseases for Oncology third edition site/ histology validation and the World Health Organization histological classification codes were used for grouping histologic subtypes as reported previously (Supplementary Tables 1-2) [24]. Histologic types of endometrial and ovarian cancers were grouped as endometrioid and nonendometrioid, and the combination patterns of the two cancer sites were assessed in this study (Supplementary Table 3).

\section{Statistical consideration}

The primary interest of analysis was to examine trends, characteristics, and survival of women with synchronous cancer in the two cohorts. The secondary interest of the analysis was to examine tumor characteristics and outcome based upon the histologic patterns of the two cancers. Continuous variables were assessed with Student $t$ test or one-way ANOVA test as appropriate. Categorical and ordinal variables were assessed with chi-square test. On multivariable analysis, binary logistic regression models were used to assess the association of SEOC and clinico-pathological factors. Patient demographics and tumor characteristics were entered in the final model.

For trend analyses of SEOC per calendar year and age at diagnosis, Joinpoint Trend Software (version 4.4.0.0, National Cancer Institute, Bethesda, MD, USA) provided by the National Cancer Institute was used to determine the potential changes in temporal trends [25]. Time duration was grouped every one year or age to provide percent frequency of collected variables. The results were analyzed with linear segmented regression test, and log-transformation was performed to determine annual percent change (APC) of the slope with 95\% confidence interval (CI) [26].

The Kaplan-Meier method was used to construct survival curves, and statistical difference between the curves were assessed with log-rank test for univariable analysis. Cox proportional hazard regression models were used to assess the independent association of SEOC and
CSS on multivariable analysis. Patient demographics and tumor characteristics were entered in the final model. Magnitudes of statistical significance were expressed with adjusted-HR and 95\%CI. All hypotheses were two-tailed, and a $P$-value of less than 0.05 was considered statistically significant. Statistical Package for Social Sciences (SPSS, version 24.0, IBM Corp, Armonk, NY, USA) was used for the analysis.

\section{RESULTS}

\section{Endometrial cancer cohort}

Among 246,736 cases of uterine cancer cases in the database, sarcoma $(n=10,578)$, metastatic tumors to the uterus from malignancy of non-uterine origin $(n=309)$, and multiple diagnosis cases (duplicated or second entry, $n=395$ ) were excluded. The remaining 235,454 cases represented primary endometrial cancer. Of those, endometrial cancer with synchronous ovarian cancer were seen in 4,082 $(1.7 \%, 95 \%$ CI 1.7-1.8) cases.

Year trends of women with endometrial cancer who had synchronous ovarian cancer were examined (Figure 1A). The proportion of synchronous ovarian cancer significantly increased from $1.1 \%$ to $2.0 \%$ between 1973 and 1983 (APC 6.72, 95\%CI 0.42-11.8, $P=0.007$ ) and then gradually decreased from $2.0 \%$ to $1.6 \%$ between 1983 and 2013 (APC -0.54, 95\%CI -2.03 to $-0.01, P=0.049$ ). For age trends (Figure 1B), the proportion of synchronous ovarian cancer increased from 3.1\% to $5.0 \%$ between 29 and 47 years of age, and then significantly decreased from $5.0 \%$ to $1.2 \%$ between 47 and 58 years of age (APC - 11.0, $95 \%$ CI -12.8 to $-9.3, P<0.001)$.

Characteristics of women with endometrial cancer who had synchronous ovarian cancer are shown in Table 1. Women with endometrial cancer who had synchronous ovarian cancer were more likely to be young and single and less likely to be of Black ethnicity (all, adjusted- $P<0.05$ ). Endometrial cancer with synchronous ovarian cancer was more likely to be stage I-II disease, endometrioid or serous histology types, grade 1-2 tumors, and small tumor size (all, adjusted- $P<0.05$ ).

Histologic patterns of endometrial cancer and synchronous ovarian cancer were examined (Table 2). The most common histologic pattern was endometrioid types in the two cancer sites seen in nearly a half (45.6\%), followed by endometrioid endometrial cancer with non-endometrioid ovarian cancer $(33.0 \%)$ and nonendometrioid types in the two cancer sites (16.1\%). Patient demographics and tumor characteristics significantly differ across the four histologic patterns (Table 2). Women with endometrial cancer were more likely to be young when the synchronous ovarian cancer was endometrioid type compared to non-endometrioid type $(P<0.001)$. The proportion of women with endometrioid histology in the two cancer sites has significantly increased from $24.2 \%$ 
to $49.9 \%$ among the synchronous cancer cases during the study period $(P<0.001)$. On the contrary, the proportion of endometrioid endometrial cancer and non-endometrioid ovarian cancer has significantly decreased during the same period (46.7\% to $28.0 \%, P<0.001$ ).
Survival analysis was performed (Table 3 ). There were 40,056 deaths due to endometrial cancer in the study population. Median follow-up time among the cases without events was 7.5 years. Women with endometrial cancer who had synchronous ovarian cancer had a 10-
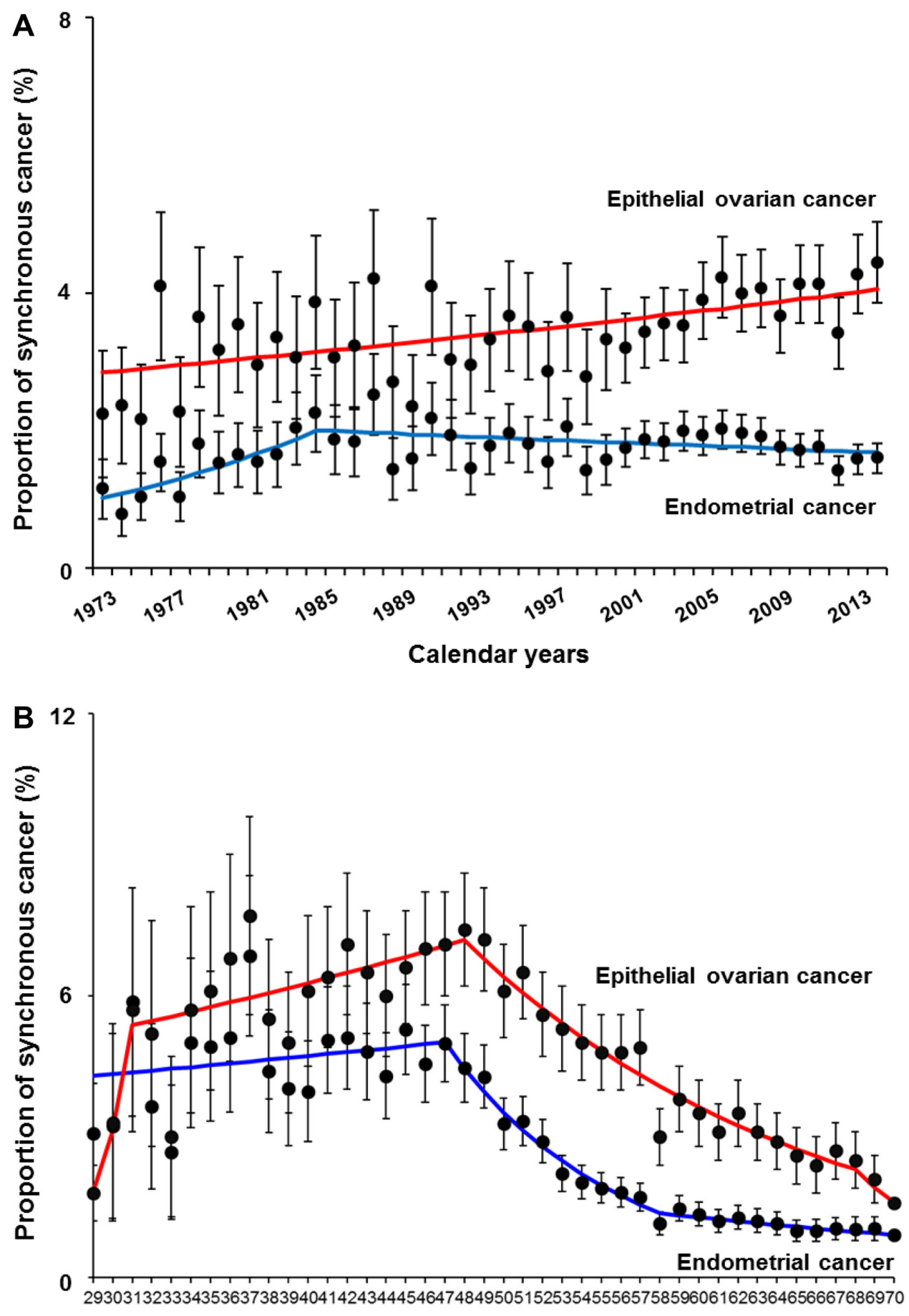

Age (years)

Figure 1: Trends of synchronous endometrial and ovarian cancer. Proportion of synchronous cancer is shown per (A) calendar year and (B) age. Blue line depicts a trend of proportion of women with endometrial cancer who had synchronous ovarian cancer. Red line depicts a trend of proportion of women with epithelial ovarian cancer who had synchronous endometrial cancer. Dots represent percent proportion and error bars represent 95\% confidence interval. Frequencies are shown in Supplementary Table 3. 
Table 1: Patient demographics

\begin{tabular}{|c|c|c|c|c|}
\hline \multirow[b]{2}{*}{ Characteristic } & \multicolumn{2}{|c|}{ Endometrial cancer cohort } & \multicolumn{2}{|c|}{ Epithelial ovarian cancer cohort } \\
\hline & $\begin{array}{c}\text { Synchronous ovarian } \\
\text { cancer }(+)\end{array}$ & $\begin{array}{c}\text { Synchronous ovarian } \\
\text { cancer (-) }\end{array}$ & $\begin{array}{c}\text { Synchronous } \\
\text { endometrial cancer }(+)\end{array}$ & $\begin{array}{c}\text { Synchronous } \\
\text { endometrial cancer (-) }\end{array}$ \\
\hline Number & $4,082(1.7 \%)$ & $231,372(98.3 \%)$ & $3,940(3.6 \%)$ & $106,123(96.4 \%)$ \\
\hline Age (y) & $56.1( \pm 12.6)$ & $63.5( \pm 12.4)$ & $55.6( \pm 12.2)$ & $62.3( \pm 14.3)$ \\
\hline$\geq 60$ & $1,484(1.0 \%)$ & $143,673(99.0 \%)$ & $1,360(2.2 \%)$ & $61,744(97.8 \%)$ \\
\hline $50-59$ & $1,255(2.1 \%)^{*}$ & $59,925(97.9 \%)$ & $1,256(4.9 \%)^{*}$ & $24,196(95.1 \%)$ \\
\hline $40-49$ & $1,010(4.7 \%)^{*}$ & $20,667(95.3 \%)$ & $1,028(6.9 \%)^{*}$ & $13,965(93.1 \%)$ \\
\hline$<40$ & $333(4.5 \%)^{*}$ & 7,107 (95.5\%) & $296(4.5 \%)$ & $6,218(95.5 \%)$ \\
\hline \multicolumn{5}{|l|}{ Ethnicity } \\
\hline White & $3,267(1.8 \%)$ & $180,070(98.2 \%)$ & $3,156(3.7 \%)$ & $83,026(96.3 \%)$ \\
\hline Black & $162(0.9 \%)^{*}$ & $17,201(99.1 \%)$ & $158(2.2 \%)^{*}$ & $7,066(97.8 \%)$ \\
\hline Hispanic & $321(1.8 \%)$ & $17,693(98.2 \%)$ & $289(3.3 \%)^{*}$ & $8,588(96.7 \%)$ \\
\hline Asian & $261(2.1 \%)^{*}$ & $11,958(97.9 \%)$ & $265(4.2 \%)^{*}$ & $5,995(95.8 \%)$ \\
\hline Others & $71(1.6 \%)^{*}$ & $4,450(98.4 \%)$ & $72(4.7 \%)$ & $1,448(95.3 \%)$ \\
\hline \multicolumn{5}{|l|}{ Marital status } \\
\hline Single & $965(2.8 \%)$ & $32,939(97.2 \%)$ & $961(6.0 \%)$ & $15,011(94.0 \%)$ \\
\hline Married & $2,113(1.7 \%)^{*}$ & $119,461(98.3 \%)$ & $2,078(3.6 \%)^{*}$ & $54,915(96.4 \%)$ \\
\hline Others & $1,004(1.3 \%)^{*}$ & $78,892(98.7 \%)$ & $901(2.4 \%)^{*}$ & 36,197 (97.6\%) \\
\hline \multicolumn{5}{|l|}{ Registry Area } \\
\hline West & $2,035(1.7 \%)$ & $118,951(98.3 \%)$ & $1,997(3.5 \%)$ & $55,049(96.5 \%)$ \\
\hline Central & $929(1.7 \%)$ & $54,469(98.3 \%)$ & $886(3.4 \%)$ & $24,800(96.5 \%)$ \\
\hline East & $1,118(1.9 \%)$ & $57,952(98.1 \%)$ & $1,057(3.9 \%)^{*}$ & $26,274(96.1 \%)$ \\
\hline \multicolumn{5}{|l|}{ Year at diagnosis } \\
\hline 1973-1979 & $264(1.3 \%)$ & 20,607 (98.7\%) & $250(2.9 \%)$ & $8,488(97.1 \%)$ \\
\hline 1980-1989 & $505(1.8 \%)^{*}$ & $26,994(98.2 \%)$ & $475(3.2 \%)$ & $14,227(96.8 \%)$ \\
\hline 1990-1999 & $692(1.7 \%)^{*}$ & $38,875(98.3 \%)$ & $681(3.3 \%)^{*}$ & $19,949(96.7 \%)$ \\
\hline 2000-2009 & $1,835(1.9 \%)^{*}$ & $96,275(98.1 \%)$ & $1,764(3.8 \%)$ & $45,258(96.2 \%)$ \\
\hline $2010-2013$ & $786(1.6 \%)^{*}$ & $48,621(98.4 \%)$ & $770(4.1 \%)$ & $18,201(95.5 \%)$ \\
\hline \multicolumn{5}{|l|}{ Stage } \\
\hline I & $2,751(1.8 \%)$ & $147,820(98.2 \%)$ & $1,972(8.5 \%)$ & $21,201(91.5 \%)$ \\
\hline II & $220(2.2 \%)^{*}$ & $9,900(97.8 \%)$ & $547(6.6 \%)$ & $7,707(93.4 \%)$ \\
\hline III & $329(1.6 \%)$ & $19,839(98.4 \%)$ & $878(2.4 \%)^{*}$ & $35,963(97.6 \%)$ \\
\hline IV & $242(1.4 \%)$ & $16,692(98.6 \%)$ & $424(1.2 \%)^{*}$ & $35,310(98.8 \%)$ \\
\hline Unknown & $540(1.4 \%)^{*}$ & $37,121(98.6 \%)$ & $119(2.0 \%)^{*}$ & $5,942(98.0 \%)$ \\
\hline \multicolumn{5}{|l|}{ Histology } \\
\hline Endometrioid & $3,185(1.8 \%)$ & $174,711(98.2 \%)$ & $2,069(16.4 \%)$ & $10,560(83.6 \%)$ \\
\hline Serous & $281(1.9 \%)^{*}$ & $14,144(98.1 \%)$ & $816(1.5 \%)^{*}$ & $55,179(98.5 \%)$ \\
\hline
\end{tabular}




\begin{tabular}{|c|c|c|c|c|}
\hline \multirow[b]{2}{*}{ Characteristic } & \multicolumn{2}{|c|}{ Endometrial cancer cohort } & \multicolumn{2}{|c|}{ Epithelial ovarian cancer cohort } \\
\hline & $\begin{array}{c}\text { Synchronous ovarian } \\
\text { cancer }(+)\end{array}$ & $\begin{array}{c}\text { Synchronous ovarian } \\
\text { cancer (-) }\end{array}$ & $\begin{array}{c}\text { Synchronous } \\
\text { endometrial cancer }(+)\end{array}$ & $\begin{array}{c}\text { Synchronous } \\
\text { endometrial cancer (-) }\end{array}$ \\
\hline Clear & $32(1.1 \%)$ & $3,003(98.9 \%)$ & $148(2.7 \%)^{*}$ & $5,392(97.3 \%)$ \\
\hline Others & $584(1.5 \%)$ & $39,514(98.5 \%)$ & $907(2.5 \%)^{*}$ & $34,992(97.5 \%)$ \\
\hline \multicolumn{5}{|l|}{ Grade } \\
\hline 1 & $1,535(1.8 \%)$ & $83,031(98.2 \%)$ & $950(10.8 \%)$ & $7,868(89.2 \%)$ \\
\hline 2 & $1,183(1.9 \%)^{*}$ & $61,203(98.1 \%)$ & $1,160(7.0 \%)^{*}$ & $15,508(93.0 \%)$ \\
\hline 3 & $631(1.3 \%)$ & $48,961(98.7 \%)$ & $913(1.9 \%)^{*}$ & $45,913(98.1 \%)$ \\
\hline Unknown & $733(1.9 \%)^{*}$ & $38,177(98.1 \%)$ & $917(2.4 \%)^{*}$ & $36,834(97.6 \%)$ \\
\hline \multicolumn{5}{|l|}{ Tumor size $(\mathrm{cm})$} \\
\hline$<2.0\left(\right.$ or $\left.10^{\dagger}\right)$ & $451(2.1 \%)$ & $21,549(98.0 \%)$ & $1,383(4.1 \%)$ & $32,098(95.9 \%)$ \\
\hline$\geq 2.0\left(\right.$ or $\left.10^{\dagger}\right)$ & $1,162(1.5 \%)^{*}$ & $78,699(98.5 \%)$ & $948(5.0 \%)^{*}$ & $18,179(95.0 \%)$ \\
\hline Unknown & $2,469(1.8 \%)$ & $134,124(98.2 \%)$ & $1,609(2.8 \%)^{*}$ & $55,846(97.2 \%)$ \\
\hline
\end{tabular}

Number (\%) per row or mean ( \pm standard deviation) is shown (per column is shown in Supplementary Table 5). All covariates were statistically significant in chi-square test on univariable analysis. ${ }^{*} P<0.05$ on multivariable analysis with binary logistic regression models (entered all the listed covariates; the top item in each covariate served as the reference). 'size cutoff for the epithelial ovarian cancer cohort.

year CSS similar to those who did not have synchronous ovarian cancer on univariable analysis $(79.4 \%$ versus $80.7 \%, P=0.59)$. However, when stratified by histologic patterns in the two cancer sites, CSS significantly differed across the combination patterns (Figure $2 \mathrm{~A}, P<0.001$ ). That is, women whose tumors had endometrioid histology in the two cancer sites had a higher 10-year CSS compared to those without synchronous ovarian cancer $(88.7 \%$ versus $80.7 \%$, adjusted-hazard ratio [HR] $0.79,95 \% \mathrm{CI}$ 0.68-0.93, $P=0.005$ ).

On the contrary, women with endometrial cancer who had synchronous non-endometrioid ovarian cancer had an increased endometrial cancer mortality compared to those without synchronous ovarian cancer: endometrial cancer with non-endometrioid ovarian cancer (10-year rates $74.2 \%$ versus $80.7 \%$, adjusted-HR $1.5895 \% \mathrm{CI}$ $1.39-1.79, P<0.001)$ and non-endometrioid histology in the two cancer sites $(62.9 \%$ versus $80.7 \%$, adjusted-HR $1.57,95 \%$ CI $1.34-1.83, P<0.001)$.

\section{Epithelial ovarian cancer cohort}

Among 133,481 cases of ovarian malignancy cases in the database, metastatic tumors to the ovary from malignancy of non-ovarian origin $(n=18,152)$, nonepithelial tumors $(n=4,451)$, sarcoma $(n=532)$, multiple diagnosis cases (duplicated or second entry, $n=276$ ), and unknown time interval due to missing data $(n=7)$ were excluded. The remaining 110,063 cases represented primary epithelial ovarian cancer, and synchronous endometrial cancer was seen in $3,940(3.6 \%, 95 \%$ CI 3.5 3.7) cases.

The proportion of epithelial ovarian cancer with synchronous endometrial cancer has significantly increased from $2.2 \%$ to $4.4 \%$ between 1973 and 2013 (APC $0.77,95 \%$ CI $0.42-1.13, P<0.001$, Figure 1A). The proportion of synchronous endometrial cancer cases among epithelial ovarian cancer increased between 31 and 48 years of age from $3.3 \%$ to $7.4 \%$ (APC $1.72,95 \% \mathrm{CI}$ $0.19-3.27, P=0.028)$ and then significantly decreased thereafter $(7.4 \%$ at 48 years to $2.5 \%$ at 68 years, APC $-5.52,95 \%$ CI -6.27 to $-4.76, P<0.001)$.

Characteristics of women with epithelial ovarian cancer who had synchronous endometrial cancer are shown in Table 1. Ovarian tumors associated with synchronous endometrial cancer were more likely to be stage I-II (incidence of synchronous endometrial cancer, 6.6-8.5\%), of endometrioid histology (16.4\%), and grade 1 tumors $(10.8 \%)$ (all, adjusted- $P<0.05)$. When synchronous cases were stratified by histologic patterns (Table 4), the proportion of women with endometrioid histology in the two cancer sites significantly increased during the study period $(24.4 \%$ to $50.1 \%, P<0.001)$. Women were more likely to be older and have advanced-stage disease when tumors were of non-endometrioid histology in the two cancer sites (both, $P<0.001$ ).

In this cohort, there were 60,798 women who died of epithelial ovarian cancer, and the median follow-up time was 5.7 years for women without events. Women with ovarian cancer who had synchronous endometrial cancer 
Table 2: Characteristics of endometrial cancer based on histology patterns of synchronous ovarian cancer

\begin{tabular}{|c|c|c|c|c|c|}
\hline & Group 1 & Group 2 & Group 3 & Group 4 & \\
\hline Endometrial cancer & Endometrioid & Endometrioid & $\begin{array}{l}\text { Non- } \\
\text { endometrioid }\end{array}$ & $\begin{array}{c}\text { Non- } \\
\text { endometrioid }\end{array}$ & $P$-value \\
\hline $\begin{array}{l}\text { Synchronous ovarian } \\
\text { cancer }\end{array}$ & Endometrioid & $\begin{array}{c}\text { Non- } \\
\text { endometrioid }\end{array}$ & Endometrioid & $\begin{array}{l}\text { Non- } \\
\text { endometrioid }\end{array}$ & \\
\hline Number & $1,737(45.6 \%)$ & $1,258(33.0 \%)$ & $200(5.2 \%)$ & $615(16.1 \%)$ & \\
\hline Age (y) & $51.8( \pm 11.2)$ & $59.1( \pm 12.2)$ & $52.2( \pm 11.2)$ & $61.7( \pm 12.6)$ & $<0.001$ \\
\hline$\geq 60$ & $369(27.2 \%)$ & $586(43.2 \%)$ & $49(3.6 \%)$ & $352(26.0 \%)$ & \\
\hline $50-59$ & $574(48.6 \%)$ & $382(32.3 \%)$ & $67(5.7 \%)$ & $158(13.4 \%)$ & \\
\hline $40-49$ & $589(61.7 \%)$ & $228(23.9 \%)$ & $61(6.4 \%)$ & $77(8.1 \%)$ & \\
\hline$<40$ & $205(64.5 \%)$ & $62(19.5 \%)$ & $23(7.2 \%)$ & $28(8.8 \%)$ & \\
\hline Ethnicity & & & & & $<0.001$ \\
\hline White & $1,368(44.7 \%)$ & $1,042(34.1 \%)$ & $161(5.3 \%)$ & $487(15.9 \%)$ & \\
\hline Black & $41(28.1 \%)$ & $55(37.7 \%)$ & $7(4.8 \%)$ & $43(29.5 \%)$ & \\
\hline Hispanic & $146(50.7 \%)$ & $79(27.4 \%)$ & $16(5.6 \%)$ & $47(16.3 \%)$ & \\
\hline Asian & $145(58.7 \%)$ & $62(25.1 \%)$ & $11(4.5 \%)$ & $29(11.7 \%)$ & \\
\hline Others & $37(52.1 \%)$ & $20(28.2 \%)$ & $5(7.0 \%)$ & $9(12.7 \%)$ & \\
\hline Marital status & & & & & $<0.001$ \\
\hline Single & $487(53.6 \%)$ & $261(28.7 \%)$ & $42(4.6 \%)$ & $118(13.0 \%)$ & \\
\hline Married & $915(45.9 \%)$ & $655(32.8 \%)$ & $127(6.4 \%)$ & $298(14.9 \%)$ & \\
\hline Others & $335(36.9 \%)$ & $342(37.7 \%)$ & $31(3.4 \%)$ & $199(21.9 \%)$ & \\
\hline Registry Area & & & & & $<0.001$ \\
\hline West & $935(49.0 \%)$ & $586(30.7 \%)$ & $107(5.6 \%)$ & $279(14.6 \%)$ & \\
\hline Central & $358(41.5 \%)$ & $294(34.1 \%)$ & $51(5.9 \%)$ & $159(18.4 \%)$ & \\
\hline East & $444(42.7 \%)$ & $378(36.3 \%)$ & $42(4.0 \%)$ & $177(17.0 \%)$ & \\
\hline Year at diagnosis & & & & & $<0.001$ \\
\hline 1973-1979 & $59(24.2 \%)$ & $114(46.7 \%)$ & $22(9.0 \%)$ & $49(20.1 \%)$ & \\
\hline 1980-1989 & $156(32.8 \%)$ & $180(37.9 \%)$ & $49(10.3 \%)$ & $90(18.9 \%)$ & \\
\hline 1990-1999 & $308(47.2 \%)$ & $219(33.5 \%)$ & $44(6.7 \%)$ & $82(12.6 \%)$ & \\
\hline $2000-2009$ & $847(49.8 \%)$ & $539(31.7 \%)$ & $57(3.3 \%)$ & $259(15.2 \%)$ & \\
\hline $2010-2013$ & $367(49.9 \%)$ & $206(28.0 \%)$ & $28(3.8 \%)$ & $135(18.3 \%)$ & \\
\hline Stage & & & & & $<0.001$ \\
\hline I & $1,244(48.2 \%)$ & $870(33.7 \%)$ & $125(4.8 \%)$ & $342(13.3 \%)$ & \\
\hline II & $111(55.2 \%)$ & $60(29.9 \%)$ & $7(3.5 \%)$ & $23(11.4 \%)$ & \\
\hline III & $142(46.3 \%)$ & $90(29.3 \%)$ & $13(4.2 \%)$ & $62(20.2 \%)$ & \\
\hline IV & $64(29.5 \%)$ & $61(28.1 \%)$ & $17(7.8 \%)$ & $75(34.6 \%)$ & \\
\hline Unknown & $176(34.9 \%)$ & $177(35.1 \%)$ & $38(7.5 \%)$ & $113(22.4 \%)$ & \\
\hline
\end{tabular}

(Continued) 


\begin{tabular}{|c|c|c|c|c|c|}
\hline & Group 1 & Group 2 & Group 3 & Group 4 & \multirow{3}{*}{$P$-value } \\
\hline Endometrial cancer & Endometrioid & Endometrioid & $\begin{array}{c}\text { Non- } \\
\text { endometrioid }\end{array}$ & $\begin{array}{c}\text { Non- } \\
\text { endometrioid }\end{array}$ & \\
\hline $\begin{array}{l}\text { Synchronous ovarian } \\
\text { cancer }\end{array}$ & Endometrioid & $\begin{array}{c}\text { Non- } \\
\text { endometrioid }\end{array}$ & Endometrioid & $\begin{array}{c}\text { Non- } \\
\text { endometrioid }\end{array}$ & \\
\hline Grade & & & & & $<0.001$ \\
\hline 1 & $779(53.8 \%)$ & $504(34.8 \%)$ & $62(4.3 \%)$ & $102(7.0 \%)$ & \\
\hline 2 & $578(52.1 \%)$ & $379(34.1 \%)$ & $55(5.0 \%)$ & $98(8.8 \%)$ & \\
\hline 3 & $159(27.2 \%)$ & $180(30.8 \%)$ & $42(7.2 \%)$ & $204(34.9 \%)$ & \\
\hline Unknown & $221(33.1 \%)$ & $195(29.2 \%)$ & $41(6.1 \%)$ & $211(31.6 \%)$ & \\
\hline Tumor size $(\mathrm{cm})$ & & & & & $<0.001$ \\
\hline$<2.0$ & $175(41.4 \%)$ & $156(36.9 \%)$ & $21(5.0 \%)$ & $71(16.8 \%)$ & \\
\hline$\geq 2.0$ & $581(54.1 \%)$ & $275(25.6 \%)$ & $53(4.9 \%)$ & $165(15.4 \%)$ & \\
\hline Unknown & $981(42.4 \%)$ & $1,258(35.8 \%)$ & $200(5.4 \%)$ & $615(16.4 \%)$ & \\
\hline
\end{tabular}

Combination patterns of endometrial cancer and synchronous epithelial ovarian cancer are displayed. Number (\%) per row or mean ( \pm standard deviation) are shown. Chi-square test for $P$-values. Significant $P$-values are emboldened.

had a significantly improved 10-year CSS compared to those without synchronous endometrial cancer $(68.3 \%$ versus $33.1 \%, P<0.001)$. When histology patterns were stratified (Figure 2B), regardless of histology type in the endometrial tumor, women whose epithelial ovarian cancer had endometrioid histology had nearly a $50 \%$ reduction in ovarian cancer mortality compared to non-synchronous cancer cases on multivariable analysis (endometrioid ovarian and endometrioid endometrial cancers, $81.9 \%$ versus $33.1 \%$, adjusted-HR $0.44,95 \%$ CI $0.39-0.50, P<0.001$; and endometrioid ovarian and non-endometrioid endometrial cancers, $76.0 \%$ versus $33.1 \%$, adjusted-HR $0.54,95 \% \mathrm{CI}$ $0.39-0.73, P<0.001)$. Similarly, if endometrial cancer is endometrioid type, regardless of ovarian cancer histology type, SEOC was associate with improved CSS compared to non-synchronous ovarian cancer (adjusted- $P<0.001$ ).

\section{DISCUSSION}

The main findings of this study are that there were significant changes in trends and characteristics of SEOC in the past decades and that the histologic pattern of endometrial and ovarian cancers impacts survival. Moreover, this study found that the peak age at diagnosis of SEOC was in the late-40's.

In our study, there was a paradoxical change in trends of endometrial cancer with synchronous ovarian cancer (decreasing) and epithelial ovarian cancer with synchronous endometrial cancer (increasing). One speculation for these trends is the demographic changes in these two cancers in the United States: decreasing incidence of ovarian cancer and increasing incidence of endometrial cancer [8-12]. Assuming that the incidence of
SEOC is constant, the relative proportion of SEOC will be decreased if incidence of endometrial cancer is increased. Conversely, if incidence of ovarian cancer is decreased, the relative proportion of SEOC will be increased.

Another speculation for these changes in trends of SEOC may be an impact of the diagnostic criteria. The reflection point of the proportion of women with endometrial cancer who had synchronous ovarian cancer was in the mid1980s, and the proportion has gradually decreased after the point (Figure 1A). This is the time at which the landmark study for the diagnostic criteria of SEOC was reported and the criteria were endorsed in subsequent years [5-7]. One may speculate that these publications may have impacted these temporal trend changes.

Prior studies have reported that $66-86 \%$ of SEOC have concordant endometrioid histology in the two cancer sites [1, 7]. Moreover, endometrioid endometrial cancer is significantly associated with increased risk of secondary primary ovarian cancer with endometrioid histology [27]. Our population-based study showed that concordant endometrioid tumors in the endometrium and the ovary were seen in nearly half of the synchronous cases thereby endorsing these previous studies. An interesting observation in our study is that the proportion of concordant endometrioid tumors in the two cancer sites among SEOC has been increasing over the time. While the exact causality is unknown, it is possible that the current approach to diagnose SEOC, relying largely upon histopathology characteristics, may have a certain limitation [28].

Specifically, distinguishing SEOC from metastatic ovarian cancer to the endometrium (or metastatic endometrial cancer to the ovary) has long been challenging, especially if the histologic type is 
Table 3: Multivariable analysis for cause-specific survival

\begin{tabular}{|c|c|c|c|c|}
\hline & \multicolumn{2}{|c|}{$\begin{array}{c}\text { Endometrial cancer with synchronous } \\
\text { ovarian cancer }\end{array}$} & \multicolumn{2}{|c|}{$\begin{array}{c}\text { Epithelial ovarian cancer with synchronous } \\
\text { endometrial cancer }\end{array}$} \\
\hline & HR $(95 \% C I)$ & $P$-value & HR $(95 \% C I)$ & $P$-value \\
\hline \multicolumn{5}{|l|}{ Age (y) } \\
\hline$<40$ & 1 & & 1 & \\
\hline $40-49$ & $1.26(1.14-1.39)$ & $<0.001$ & $1.51(1.43-1.59)$ & $<0.001$ \\
\hline $50-59$ & $1.61(1.47-1.76)$ & $<0.001$ & $1.82(1.73-1.91)$ & $<0.001$ \\
\hline$\geq 60$ & $3.39(3.10-3.71)$ & $<0.001$ & $2.77(2.65-2.91)$ & $<0.001$ \\
\hline \multicolumn{5}{|l|}{ Ethnicity } \\
\hline White & 1 & & 1 & \\
\hline Black & $1.75(1.69-1.80)$ & $<0.001$ & $1.21(1.17-1.25)$ & $<0.001$ \\
\hline Hispanic & $1.13(1.09-1.18)$ & $<0.001$ & $0.97(0.94-1.01)$ & 0.11 \\
\hline Asian & $0.97(0.92-1.02)$ & 0.26 & $0.91(0.87-0.95)$ & $<0.001$ \\
\hline Others & $1.06(0.97-1.15)$ & 0.20 & $0.96(0.90-1.04)$ & 0.34 \\
\hline \multicolumn{5}{|l|}{ Marital status } \\
\hline Single & 1 & & 1 & \\
\hline Married & $0.82(0.80-0.85)$ & $<0.001$ & $0.86(0.83-0.88)$ & $<0.001$ \\
\hline Others & $1.16(1.13-1.20)$ & $<0.001$ & $1.08(1.05-1.11)$ & $<0.001$ \\
\hline \multicolumn{5}{|l|}{ Registry Area } \\
\hline West & 1 & & 1 & \\
\hline Central & $1.05(1.03-1.08)$ & 0.011 & $1.06(1.04-1.08)$ & $<0.001$ \\
\hline East & $1.03(1.01-1.06)$ & 0.009 & $0.94(0.92-0.96)$ & $<0.001$ \\
\hline \multicolumn{5}{|l|}{ Year at diagnosis } \\
\hline 1973-1979 & 1 & & 1 & \\
\hline 1980-1989 & $1.28(1.23-1.34)$ & $<0.001$ & $1.00(0.96-1.03)$ & 0.89 \\
\hline 1990-1999 & $1.56(1.49-1.63)$ & $<0.001$ & $1.05(1.01-1.08)$ & 0.005 \\
\hline 2000-2009 & $1.58(1.51-1.64)$ & $<0.001$ & $1.01(0.98-1.04)$ & 0.48 \\
\hline 2010-2013 & $1.53(1.45-1.61)$ & $<0.001$ & $0.84(0.81-0.88)$ & $<0.001$ \\
\hline \multicolumn{5}{|l|}{ Stage } \\
\hline I & 1 & & 1 & \\
\hline II & $3.04(2.90-3.19)$ & $<0.001$ & $2.57(2.44-2.70)$ & $<0.001$ \\
\hline III & $6.19(5.99-6.39)$ & $<0.001$ & $5.73(5.52-5.94)$ & $<0.001$ \\
\hline IV & $19.4(18.9-20.0)$ & $<0.001$ & $9.21(8.88-9.54)$ & $<0.001$ \\
\hline Unknown & $4.07(3.95-4.21)$ & $<0.001$ & $6.23(5.95-6.53)$ & $<0.001$ \\
\hline \multicolumn{5}{|l|}{ Tumor size $(\mathrm{cm})$} \\
\hline$<2.0\left(\right.$ or $\left.10^{*}\right)$ & 1 & & 1 & \\
\hline$\geq 2.0\left(\right.$ or $\left.10^{*}\right)$ & $1.78(1.68-1.89)$ & $<0.001$ & $0.94(0.92-0.97)$ & $<0.001$ \\
\hline Unknown & $1.86(1.76-1.97)$ & $<0.001$ & $1.29(1.26-1.31)$ & $<0.001$ \\
\hline
\end{tabular}




\begin{tabular}{lcccc} 
& HR (95\%CI) & $\boldsymbol{P}$-value & HR (95\%CI) & $P$-value \\
\hline Histology patterns & & & & \\
Non-synchronous & 1 & & 1 & \\
Group 1 (E/E) & $0.79(0.68-0.93)$ & $\mathbf{0 . 0 0 5}$ & $0.44(0.39-0.50)$ & $<\mathbf{0 . 0 0 1}$ \\
Group 2 (E/NE) & $1.58(1.39-1.79)$ & $<\mathbf{0 . 0 0 1}$ & $0.54(0.39-0.73)$ & $<\mathbf{0 . 0 0 1}$ \\
Group 3 (NE/E) & $0.94(0.66-1.34)$ & 0.73 & $0.78(0.70-0.86)$ & $<\mathbf{0 . 0 0 1}$ \\
Group 4 (NE/NE) & $1.57(1.34-1.83)$ & $<\mathbf{0 . 0 0 1}$ & $0.96(0.85-1.10)$ & 0.57 \\
\hline
\end{tabular}

Cox proportional hazard regression models for cause-specific survival. All the listed covariates were entered in the final models. Significant $P$-values are emboldened. Unadjusted-HR is listed in Supplementary Table 6. "cutoff for ovarian cancer. thistology types for the primary tumor followed by the synchronous tumor are shown inside the brackets. Abbreviations: HR, hazard ratio; CI, confidence interval; E, endometrioid; and NE, non-endometrioid.

concordant in the two cancer sites such as endometrioid tumors [29-31]. Recent studies have shown that the concordance rate between histopathologic diagnosis and molecular diagnosis was considerably low, and it may be possible that the cases that met the diagnostic criteria for SEOC were actually metastatic endometrial cancer to the ovary or vice versa [29-31]. Integrating molecular diagnosis to differentiate synchronous versus metastatic cases would be useful in the proper diagnosis of SEOC [32, 33].

SEOC has been thought to be a disease of young women [4]. Our results are more specific to show that the proportion of SEOC increased to the late-40s and then decreased thereafter (Figure 1B), highlighting that SEOC is indeed a disease of middle-aged women. One hypothesis to link this association is the possibility of Lynch syndrome. The mean age of endometrial cancer diagnosis in women with Lynch syndrome is in the late40s (47-49 years) and the mean age of ovarian cancer in women with Lynch syndrome is also in the 40s (4249 years) [34]. Moreover, the incidence of synchronous endometrial cancer in ovarian cancer among women with Lynch syndrome is reported as $21.5 \%$ [35]. Collectively, genetic assessment and testing is highly recommended for women with SEOC.

The clinical outcome of women with SEOC seems inconsistent between studies. Some studies concluded that women with SEOC have a favorable prognosis while others have concluded that no difference in prognosis to non-synchronous endometrial or ovarian cancer $[1,7$, 36]. Because these previous studies were either lacking a control group or were conducted with limited sample sizes, our study is more informative in that survival of SEOC largely depends on the histologies of the two cancer sites.

There are various strengths of this study. First, this is a population-based study linking multiple datasets for endometrial and ovarian cancers by examining the
SEER Program. Second, this study examined nearly four decades of cases to evaluate time trends of synchronous tumors, providing clinically meaningful information regarding this disease entity. Last, histology pattern was examined in both endometrial and ovarian cancer in this study. Limitations of this study include the fact that central pathology review was not performed to confirm the diagnosis of SEOC versus metastatic tumors from endometrial or ovarian cancer. As described above, lack of central pathology review including clonality analysis results in possible over-diagnosis of SEOC. Information for molecular clonality analysis was not available in this database. In addition, this database does not have genetic information available. Thus, it remains unknown what percentage of women with SEOC had Lynch syndrome. This study was conducted only for a US population; thus, generalizability or our results in other population remains unknown and merits further study.

A weakness of the study is the arbitrary cutoff used to define the SEOC. One may be concerned that the cutoff of a 4-month time difference between the two cancer diagnoses may be too liberal. However, we have chosen this cutoff based on a theoretical rationale described earlier. In a post-hoc analysis, we examined a stricter cutoff of a 2-month time difference between the two cancer diagnoses. Similar results were re-demonstrated for SEOC trends per calendar year and patient age (Supplementary Figure 2A-2B).

Last, survival analysis in SEOC would be challenging in various aspects. First, if the histology types of the two cancer sites are concordant, it will be likely difficult to determine the actual attribution of cause of death, particularly when both cancers are early-stage. Second, when the patient has a short follow-up time, it will be unknown whether the patient will develop a secondary primary malignancy [37]. In our study, we used a fairly short cutoff of 4-month interval for defining SEOC and thus this time-lead bias would be most likely minimized. 

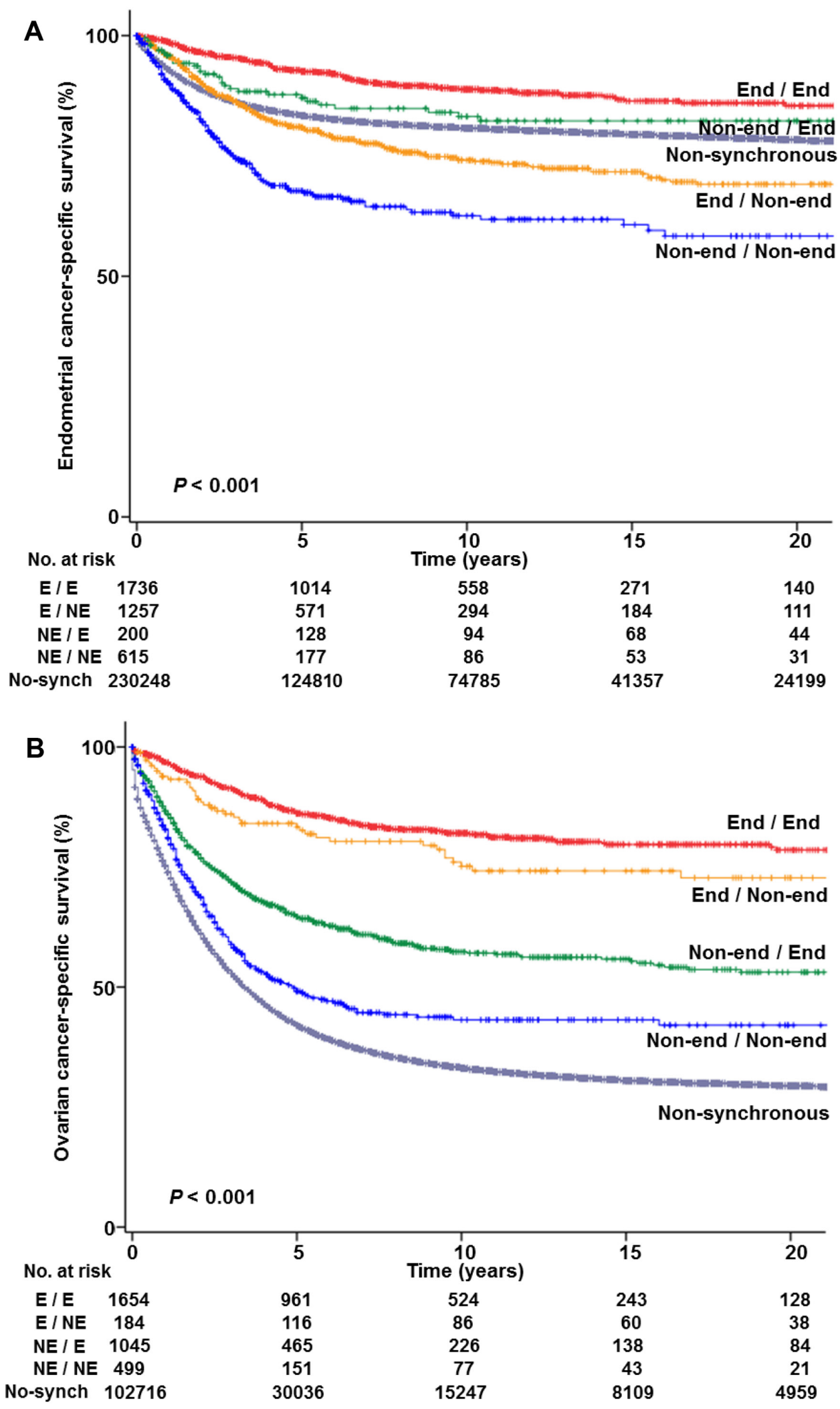

Figure 2: Cause-specific survival curves based on histologic patterns. Log-rank test for $P$-values. (A) Endometrial cancerspecific survival in the endometrial cancer cohort and (B) ovarian cancer-specific survival in the epithelial ovarian cancer cohort are shown based on histology patterns in the two tumor sites (primary tumor site / synchronous tumor site; Supplementary Table 4). Abbreviations: End, endometrioid; and non-end, non-endometrioid. 
Table 4: Characteristics of epithelial ovarian cancer based on histology patterns of synchronous endometrial cancer

\begin{tabular}{|c|c|c|c|c|c|}
\hline & Group 1 & Group 2 & Group 3 & Group 4 & \\
\hline Ovarian cancer & Endometrioid & Endometrioid & $\begin{array}{l}\text { Non- } \\
\text { endometrioid }\end{array}$ & $\begin{array}{l}\text { Non- } \\
\text { endometrioid }\end{array}$ & $P$-value \\
\hline $\begin{array}{l}\text { Synchronous } \\
\text { endometrial cancer }\end{array}$ & Endometrioid & $\begin{array}{c}\text { Non- } \\
\text { endometrioid }\end{array}$ & Endometrioid & $\begin{array}{c}\text { Non- } \\
\text { endometrioid }\end{array}$ & \\
\hline Number & $1,847(46.9 \%)$ & $222(5.6 \%)$ & $1,227(31.1 \%)$ & $644(16.3 \%)$ & \\
\hline Age (y) & $52.0( \pm 11.2)$ & $53.2( \pm 11.8)$ & $58.6( \pm 12.0)$ & $61.3( \pm 12.0)$ & $<0.001$ \\
\hline$\geq 60$ & $393(28.9 \%)$ & $63(4.6 \%)$ & $547(40.2 \%)$ & $357(26.3 \%)$ & \\
\hline $50-59$ & $627(49.9 \%)$ & $65(5.2 \%)$ & $383(30.5 \%)$ & $181(14.4 \%)$ & \\
\hline $40-49$ & $630(61.3 \%)$ & $70(6.8 \%)$ & $243(23.6 \%)$ & $85(8.3 \%)$ & \\
\hline$<40$ & $197(66.6 \%)$ & $24(8.1 \%)$ & $54(18.2 \%)$ & $21(7.1 \%)$ & \\
\hline Ethnicity & & & & & $<0.001$ \\
\hline White & $1,473(46.7 \%)$ & $178(5.6 \%)$ & $1,007(31.9 \%)$ & $498(15.8 \%)$ & \\
\hline Black & $47(29.7 \%)$ & $8(5.1 \%)$ & $54(34.2 \%)$ & $49(31.0 \%)$ & \\
\hline Hispanic & $142(49.1 \%)$ & $20(6.9 \%)$ & $75(26.0 \%)$ & $52(18.0 \%)$ & \\
\hline Asian & $148(55.8 \%)$ & $11(4.2 \%)$ & $72(27.2 \%)$ & $34(12.8 \%)$ & \\
\hline Others & $37(51.4 \%)$ & $5(6.9 \%)$ & $19(26.4 \%)$ & $11(15.3 \%)$ & \\
\hline Marital status & & & & & $<0.001$ \\
\hline Single & $519(54.0 \%)$ & $47(4.9 \%)$ & $266(27.7 \%)$ & $129(13.4 \%)$ & \\
\hline Married & $973(46.8 \%)$ & $135(6.5 \%)$ & $652(31.4 \%)$ & $318(15.3 \%)$ & \\
\hline Others & $355(39.4 \%)$ & $40(4.4 \%)$ & $309(34.3 \%)$ & $197(21.9 \%)$ & \\
\hline Registry Area & & & & & $<0.001$ \\
\hline West & $998(50.0 \%)$ & $122(6.1 \%)$ & $562(28.1 \%)$ & $315(15.8 \%)$ & \\
\hline Central & $384(43.3 \%)$ & $52(5.9 \%)$ & $289(32.6 \%)$ & $161(18.2 \%)$ & \\
\hline East & $465(44.0 \%)$ & $48(4.5 \%)$ & $376(35.6 \%)$ & $168(15.9 \%)$ & \\
\hline Year at diagnosis & & & & & $<0.001$ \\
\hline 1973-1979 & $61(24.4 \%)$ & $25(10.0 \%)$ & $110(44.0 \%)$ & $54(21.6 \%)$ & \\
\hline 1980-1989 & $165(34.7 \%)$ & $48(10.1 \%)$ & $173(36.4 \%)$ & $89(18.7 \%)$ & \\
\hline 1990-1999 & $334(49.0 \%)$ & $50(7.3 \%)$ & $203(29.8 \%)$ & $94(13.8 \%)$ & \\
\hline 2000-2009 & $901(51.1 \%)$ & $64(3.6 \%)$ & $534(30.3 \%)$ & $265(15.0 \%)$ & \\
\hline 2010-2013 & $386(50.1 \%)$ & $35(4.5 \%)$ & $207(26.9 \%)$ & $142(18.4 \%)$ & \\
\hline Stage & & & & & $<0.001$ \\
\hline $\mathrm{I}$ & $1,132(57.4 \%)$ & $125(6.3 \%)$ & $506(25.7 \%)$ & $209(10.6 \%)$ & \\
\hline II & $295(53.9 \%)$ & $29(5.3 \%)$ & $155(28.3 \%)$ & $68(12.4 \%)$ & \\
\hline III & $284(32.3 \%)$ & $45(5.1 \%)$ & $341(38.8 \%)$ & $208(23.7 \%)$ & \\
\hline IV & $102(24.1 \%)$ & $20(4.7 \%)$ & $176(41.5 \%)$ & $126(29.7 \%)$ & \\
\hline Unknown & $34(28.6 \%)$ & $3(2.5 \%)$ & $49(41.2 \%)$ & $33(27.7 \%)$ & \\
\hline
\end{tabular}

(Continued) 


\begin{tabular}{|c|c|c|c|c|c|}
\hline & Group 1 & Group 2 & Group 3 & Group 4 & \multirow{3}{*}{$P$-value } \\
\hline Ovarian cancer & Endometrioid & Endometrioid & $\begin{array}{c}\text { Non- } \\
\text { endometrioid }\end{array}$ & $\begin{array}{c}\text { Non- } \\
\text { endometrioid }\end{array}$ & \\
\hline $\begin{array}{l}\text { Synchronous } \\
\text { endometrial cancer }\end{array}$ & Endometrioid & $\begin{array}{c}\text { Non- } \\
\text { endometrioid }\end{array}$ & Endometrioid & $\begin{array}{c}\text { Non- } \\
\text { endometrioid }\end{array}$ & \\
\hline Grade & & & & & $<0.001$ \\
\hline 1 & $604(63.6 \%)$ & $69(7.3 \%)$ & $191(20.1 \%)$ & $86(9.1 \%)$ & \\
\hline 2 & $688(59.3 \%)$ & $69(5.9 \%)$ & $284(24.5 \%)$ & $119(10.3 \%)$ & \\
\hline 3 & $261(28.6 \%)$ & $30(3.3 \%)$ & $379(41.5 \%)$ & $243(26.6 \%)$ & \\
\hline Unknown & $294(32.1 \%)$ & $54(5.9 \%)$ & $373(40.7 \%)$ & $196(21.4 \%)$ & \\
\hline Tumor size $(\mathrm{cm})$ & & & & & $<0.001$ \\
\hline$<10$ & $640(46.3 \%)$ & $83(6.0 \%)$ & $417(30.2 \%)$ & $243(17.6 \%)$ & \\
\hline$\geq 10$ & $550(58.0 \%)$ & $43(4.5 \%)$ & $247(26.1 \%)$ & $108(11.4 \%)$ & \\
\hline Unknown & $657(40.8 \%)$ & $96(6.0 \%)$ & $563(35.0 \%)$ & $293(18.2 \%)$ & \\
\hline
\end{tabular}

Combination patterns of epithelial ovarian cancer and synchronous endometrial cancer are displayed. Number (\%) per row or mean ( \pm standard deviation) are shown. Chi-square test for $P$-values. Significant $P$-values are emboldened.

A clinical implication of our results is in the area of surgical management and planning. First, while supracervical hysterectomy is suggested as an alternative mode of hysterectomy in the management of women with epithelial ovarian cancer [38], it will be reasonable to perform total hysterectomy given that considerable fractions of women with epithelial ovarian cancer may have a concurrent endometrial cancer. If supracervical hysterectomy is performed, tumor cells from the endometrial cancer left in the cervical stump or the cervix can be the source of residual tumors resulting in decreased survival outcome [39]. Therefore, if supracervical hysterectomy for ovarian cancer is planned, preoperative assessment of endometrial pathology may be a reasonable approach to rule out synchronous endometrial cancer. Similarly, when fertility preservation is considered for young women with apparent stage I epithelial ovarian cancer, evaluation of endometrial pathology is an important preoperative assessment to rule out synchronous endometrial cancer [40].

Second, if young women with clinically early-stage low-grade endometrial cancer desire future fertility with a non-surgical approach, evaluation of adnexal pathology is necessary as a routine pretreatment evaluation given that younger reproductive age women have higher risk of synchronous ovarian cancer. If imaging or biomarker testing suspects the presence of synchronous ovarian cancer, non-surgical approaches would not be advisable. Similarly, a thorough and careful intraoperative assessment of the adnexa is recommended for young women who desire ovarian preservation for clinical early-stage lowgrade endometrial cancer [24].

\section{CONFLICTS OF INTEREST}

Dr. Wright has served as a consultant for Clovis Oncology and Tesaro. Dr. Rimel has served as a consultant for Tesaro, AstraZeneca, and Genentech. The other authors have nothing to disclose.

\section{FINANCIAL SUPPORT}

Ensign Endowment for Gynecologic Cancer Research (K.M.).

\section{REFERENCES}

1. Zaino R, Whitney C, Brady MF, DeGeest K, Burger RA, Buller RE. Simultaneously detected endometrial and ovarian carcinomas - a prospective clinicopathologic study of 74 cases: a gynecologic oncology group study. Gynecol Oncol. 2001; 83:355-62.

2. Chiang YC, Chen CA, Huang CY, Hsieh CY, Cheng WF. Synchronous primary cancers of the endometrium and ovary. Int J Gynecol Cancer. 2008; 18:159-64.

3. Williams MG, Bandera EV, Demissie K, RodriguezRodriguez L. Synchronous primary ovarian and endometrial cancers: a population-based assessment of survival. Obstet Gynecol. 2009; 113:783-9.

4. AlHilli MM, Dowdy SC, Weaver AL, St Sauver JL, Keeney GL, Mariani A, Podratz KC, Bakkum-Gamez JN. Incidence and factors associated with synchronous ovarian and endometrial cancer: a population-based case-control study. Gynecol Oncol. 2012; 125:109-13. 
5. Ulbright TM, Roth LM. Metastatic and independent cancers of the endometrium and ovary: a clinicopathologic study of 34 cases. Hum Pathol. 1985; 16:28-34.

6. Scully RE, Young RH, Clement PB. Tumors of the ovary, maldeveloped gonads, fallopian tube, and broad ligament. Atlas of tumor pathology. Bethesda, MD: Armed Forces Institute of Pathology; 1998.

7. Soliman PT, Slomovitz BM, Broaddus RR, Sun CC, Oh JC, Eifel PJ, Gershenson DM, Lu KH. Synchronous primary cancers of the endometrium and ovary: a single institution review of 84 cases. Gynecol Oncol. 2004; 94:456-62.

8. Centers for Disease Control and Prevention. National Center for Health Statistics. <https://www.cdc.gov/nchs/ data/hestat/overweight/overweight_adult.htm $>$ (accessed 5/20/2017).

9. National Cancer Institute, Surveillance, Epidemiology, and End Results Program. Cancer Stat Facts: Endometrial cancer. https://seer.cancer.gov/statfacts/html/corp.html (accessed 5/20/2017).

10. National Cancer Institute, Surveillance, Epidemiology, End Results Program. Cancer Stat Facts: Ovarian cancer. $<$ https://seer.cancer.gov/statfacts/html/ovary.html > (accessed 5/20/2017).

11. Morris CR, Rodriguez AO, Epstein J, Cress RD. Declining trends of epithelial ovarian cancer in California. Gynecol Oncol. 2008; 108:207-13.

12. Yang HP, Anderson WF, Rosenberg PS, Trabert B, Gierach GL, Wentzensen N, Cronin KA, Sherman ME. Ovarian cancer incidence trends in relation to changing patterns of menopausal hormone therapy use in the United States. J Clin Oncol. 2013; 31:2146-51.

13. The Surveillance, Epidemiology, and End Results (SEER) Program of the National Cancer Institute. https://seer. cancer.gov/ (accessed 5/20/2017).

14. National Cancer Registrars Association. http://www.ncrausa.org/ (accessed 5/20/2017).

15. von Elm E, Altman DG, Egger M, Pocock SJ, Gotzsche PC, Vandenbroucke JP. Strengthening the Reporting of Observational Studies in Epidemiology (STROBE) statement: guidelines for reporting observational studies. BMJ. 2007; 335:806-8.

16. Matsuo K, Machida H, Stone RL, Soliman PT, Thaker PH, Roman LD, Wright JD. Risk of subsequent ovarian cancer after ovarian conservation in young women with stage I endometrioid endometrial cancer. Obstet Gynecol. 2017; 130:403-410.

17. Matsuo K, Machida H, Horowitz MP, Shahzad MMK, Guntupalli SR, Roman LD, Wright JD. Risk of metachronous ovarian cancer after ovarian conservation in young women with stage I cervical cancer. Am J Obstet Gynecol. 2017; 217:580.e1-580.e10.

18. Matsuo K, Machida H, Frimer M, Marcus JZ, Pejovic T, Roman LD, Wright JD. Prognosis of women with stage I endometrioid endometrial cancer and synchronous stage
I endometrioid ovarian cancer. Gynecol Oncol. 2017; 147:558-564.

19. Elit LM, O'Leary EM, Pond GR, Seow HY. Impact of wait times on survival for women with uterine cancer. J Clin Oncol. 2013; 32:27-33.

20. Shalowitz DI, Epstein AJ, Buckingham L, Ko EM, Giuntoli RL 2nd. Survival implications of time to surgical treatment of endometrial cancers. Am J Obstet Gynecol. 2017; 216:268 e1-268 e18.

21. Matsuo K, Opper NR, Ciccone MA, Garcia J, Tierney KE, Baba T, Muderspach LI, Roman LD. Time interval between endometrial biopsy and surgical staging for type I endometrial cancer: association between tumor characteristics and survival outcome. Obstet Gynecol. 2015; 125:424-33.

22. National Death Index. https://www.cdc.gov/nchs/ndi/ (accessed 5/20/2017).

23. Edge SB, Byrd DR, Compton CC, Fritz AG, Greene FL, Trotti A, editors. AJCC cancer staging manual. 7th ed. New York: Springer; 2010.

24. Matsuo K, Machida H, Shoupe D, Melamed A, Muderspach LI, Roman LD, Wright JD. Ovarian Conservation and Overall Survival in Young Women With Early-Stage Low-Grade Endometrial Cancer. Obstet Gynecol. 2016; 128:761-70.

25. National Cancer Instititute Joinpoint Trend Analysis Software. $\quad<$ http://surveillance.cancer.gov/joinpoint $>$ (accessed 5/20/2017).

26. Kim HJ, Fay MP, Feuer EJ, Midthune DN. Permutation tests for joinpoint regression with applications to cancer rates. Stat Med. 2000; 19:335-51.

27. Chen T, Brenner H, Fallah M, Jansen L, Castro FA, Geiss K, Holleczek B, Katalinic A, Luttmann S, Sundquist K, Ressing M, Xu L, Hemminki K. Risk of second primary cancers in women diagnosed with endometrial cancer in German and Swedish cancer registries. Int J Cancer. 2017; 141:2270-2280.

28. Chao A, Wu RC, Jung SM, Lee YS, Chen SJ, Lu YL, Tsai CL, Lin CY, Tang YH, Chen MY, Huang HJ, Chou HH, Huang KG, et al. Implication of genomic characterization in synchronous endometrial and ovarian cancers of endometrioid histology. Gynecol Oncol. 2016; 143:60-7.

29. Brinkmann D, Ryan A, Ayhan A, McCluggage WG, Feakins R, Santibanez-Koref MF, Mein CA, Gayther SA, Jacobs IJ. A molecular genetic and statistical approach for the diagnosis of dual-site cancers. J Natl Cancer Inst. 2004; 96:1441-6.

30. Schultheis AM, Ng CK, De Filippo MR, Piscuoglio S, Macedo GS, Gatius S, Perez Mies B, Soslow RA, Lim RS, Viale A, Huberman KH, Palacios JC, Reis-Filho JS, et al. Massively Parallel Sequencing-Based Clonality Analysis of Synchronous Endometrioid Endometrial and Ovarian Carcinomas. J Natl Cancer Inst. 2016; 108:djv427.

31. Anglesio MS, Wang YK, Maassen M, Horlings HM, Bashashati A, Senz J, Mackenzie R, Grewal DS, Li-Chang 
H, Karnezis AN, Sheffield BS, McConechy MK, Kommoss F, et al. Synchronous Endometrial and Ovarian Carcinomas: Evidence of Clonality. J Natl Cancer Inst. 2016; 108:djv428.

32. Ramus SJ, Elmasry K, Luo Z, Gammerman A, Lu K, Ayhan A, Singh N, McCluggage WG, Jacobs IJ, Whittaker JC, Gayther SA. Predicting clinical outcome in patients diagnosed with synchronous ovarian and endometrial cancer. Clin Cancer Res. 2008; 14:5840-8.

33. Ikeda Y, Oda K, Nakagawa S, Murayama-Hosokawa S, Yamamoto S, Ishikawa S, Wang L, Takazawa Y, Maeda D, Wada-Hiraike O, Kawana K, Fukayama M, Aburatani $\mathrm{H}$, et al. Genome-wide single nucleotide polymorphism arrays as a diagnostic tool in patients with synchronous endometrial and ovarian cancer. Int $\mathrm{J}$ Gynecol Cancer. 2012; 22:725-31.

34. Committee on Practice Bulletins-Gynecology; Society of Gynecologic Oncology. ACOG Practice Bulletin No. 147: Lynch syndrome. Obstet Gynecol. 2014; 124:1042-54.

35. Watson P, Butzow R, Lynch HT, Mecklin JP, Jarvinen HJ, Vasen HF, Madlensky L, Fidalgo P, Bernstein I. The clinical features of ovarian cancer in hereditary nonpolyposis colorectal cancer. Gynecol Oncol. 2001; 82:223-8.
36. Heitz F, Amant F, Fotopoulou C, Battista MJ, Wimberger P, Traut A, Fisseler-Eckhoff A, Harter P, Vandenput I, Sehouli J, Schmidt M, Kimmig R, du Bois R, du Bois A. Synchronous ovarian and endometrial cancer-an international multicenter case-control study. Int J Gynecol Cancer. 2013; 24:54-60.

37. Rosso S, De Angelis R, Ciccolallo L, Carrani E, Soerjomataram I, Grande E, Zigon G, Brenner H; EUROCARE Working Group. Multiple tumours in survival estimates. Eur J Cancer. 2009; 45:1080-94.

38. Milam MR, Sood AK, King S, Bassett RL Jr, Lu KH, Slomovitz BM, Coleman RL, Ramirez PT. Supracervical hysterectomy in patients with advanced epithelial ovarian cancer. Obstet Gynecol. 2007; 109:641-6.

39. Matsuo K, Machida H, Takiuchi T, Garcia-Sayre J, Yessaian AA, Roman LD. Prognosis of women with apparent stage I endometrial cancer who had supracervical hysterectomy. Gynecol Oncol. 2017; 145:41-49.

40. Wright JD, Shah M, Mathew L, Burke WM, Culhane J, Goldman N, Schiff PB, Herzog TJ. Fertility preservation in young women with epithelial ovarian cancer. Cancer. 2009; $115: 4118-26$. 